\title{
Structural Changes of the Lipid Model Systems in the Presence of Enzymes or Silver Nanoparticles
}

\author{
Sergei Yu. Zaitsev ${ }^{1}\left(\mathbb{D}\right.$, Ilia S. Zaitsev ${ }^{2} \mathbb{( D )}$, Irina V. Milaeva ${ }^{3, *(\mathbb{D}}$ \\ 1 Federal Research Center for Animal Husbandry named after Academy Member L.K. Ernst, Dubrovitsy 60, \\ Podolsk Municipal District, Moscow Region, 142132 Russian Federation, 142132 Russian Federation; \\ s.y.zaitsev@mail.ru (S.Y.Z.); \\ 2 Shemyakin-Ovchinnikov Institute of Bioorganic Chemistry of the Russian Academy of Sciences, Miklukho-Maklaya Str. \\ 16/10, Moscow 117997, Russian Federation; chemil@inbox.ru (I.S.Z.); \\ 3 Chemistry Department, Federal State Budgetary Educational Institution of Higher Education "Moscow State Academy of \\ Veterinary Medicine and Biotechnology - MVA after K.I. Skryabin", Skryabin Str.23, 109472 Moscow, Russian \\ Federation; ira-gurievich@list.ru (I.V.M.); \\ * Correspondence: s.y.zaitsev@mail.ru (S.Y.Z.);
}

Scopus Author ID 7103012267

Received: 1.03.2021; Revised: 1.04.2021; Accepted: 3.04.2021; Published: 9.04.2021

\begin{abstract}
This work aimed to study the interaction of silver nanoparticles (AgNP) and lipases with models of biological membranes based on natural phospholipid and cholesterol. The crude phosphatidylcholine from egg yolk (PCe1) and synthetic cholesterol (Chol) were obtained from SigmaAldrich. Porcine pancreatic lipase (PPL) was obtained by purification from the hog pancreas. AgNP dispersion was prepared by the well-known citrate method. Measurement of surface tension (ST) was carried out using a BPA-1P device. The equilibrium surface tension (eST) was obtained by calculating the ST-time isotherms using the ADSA program. The particle sizes were determined by the dynamic light scattering method. An addition of AgNPs led to a pronounced decrease in both ST and eST (whereas almost no changes occurred by lipase addition), and AgNPs destructed the large lipid particles. The average lipid particle diameter values changed drastically, whereas the effective particle diameter values were almost the same by lipase addition. Thus, the interactions of AgNPs or lipase with the mixture of natural phospholipid and cholesterol have had entirely different features. These effects are interesting for modeling the interactions of inorganic and organic compounds with biological membranes.
\end{abstract}

Keywords: lipids; silver nanoparticles; porcine pancreatic lipase; surface tension; particle sizes; dynamic light scattering.

(C) 2021 by the authors. This article is an open-access article distributed under the terms and conditions of the Creative Commons Attribution (CC BY) license (https://creativecommons.org/licenses/by/4.0/).

\section{Introduction}

Interfacial properties of biologically active compounds (phospholipids, cholesterols, membrane proteins, peptides, etc.) are very important for studying the biological membranes' structure-function. In recent years, the study of the properties and applications of silver nanoparticles (AgNPs) is of high interest [1-3]. The antimicrobial effects of silver ions and their salts are well known [4]. The high activity of nanoparticles is due to their small size and highly developed interfacial surface, strong adsorption properties, the presence of unsaturated metal valences, and the formation of a large set of «chelate» compounds [5-7]. This opens up the possibility of nanomaterial applications in the fields of biomedicine, pharmacology, food, and agricultural production [2, 4-7]. The effects of nanoparticles on biological objects are 
currently controversial and have not been definitively evaluated in many cases. In the available literature, the opinion is increasingly expressed that various nanoparticles, under certain conditions, can negatively affect the course of several biochemical processes in a living organism [2-4].

The synthesis and properties of silver nanoparticles and the achievements and prospects of their use are well described in Russian [4-7] and foreign [8-10] publications. Besides, it is quite convenient to work with silver nanoparticles when studying several biochemical processes [11-20].

There are numerous reviews [21-26] on purification, structure-function relations, immobilization, and application of various lipases that are not a subject to discuss. It is important to highlight that lipase preparations are widely used in biotechnology and biomedicine, especially for therapy of the pancreas, liver, and gallbladder diseases [27-32]. The study of the effect of lipase interaction with lipid vesicles in aqueous dispersions is of fundamental and practical interest.

This work aimed to study AgNPs and lipases' interaction with biological membranes' models based on natural phospholipid and cholesterol.

\section{Materials and Methods}

The following compounds and reagents from Sigma-Aldrich were used in this work: crude phosphatidylcholine from egg yolk (PCe1) and synthetic cholesterol (Chol). A dispersion of silver nanoparticles (AgNPs) was obtained by the well-known citrate method [4]. Measurement of surface tension (ST) was carried out using a BPA-1P device by measuring the maximum pressure in a bubble with a surface lifetime of $0.5 \mathrm{~s}$ to $7 \mathrm{~s}$ [33]. The equilibrium surface tension (eST) was obtained by calculating the ST-time isotherms using the ADSA program [33]. The particle sizes in the obtained colloidal solutions (i.e., AgNP dispersions) were determined by the method of dynamic light scattering. Porcine pancreatic lipase (PPL) was obtained by purification from the hog pancreas by well-known methods [21-22]. The data obtained were subjected to the statistical treatment by STATISTICA 10 (the average errors were below $1 \%$ ).

\section{Results and Discussion}

The surface tension (ST) and particle size values of two-component mixtures of phosphatidylcholine and cholesterol (as models of lipid biomembranes) were investigated in the presence of silver nanoparticles or PPL at the same concentration level.

\subsection{Surface tension changes by the interaction of AgNPs with model membranes.}

The surface tension (ST) values of the mixtures of phosphatidylcholine with cholesterol were investigated in the presence of silver nanoparticles. In many samples of individual PCe1:Chol dispersions (i.e., without the addition of nanoparticles), the following reference data were obtained: a) $72.20 \pm 0.11 \mathrm{mN} / \mathrm{m}$ (ST) with a surface lifetime of 0.5 s (i.e., in the range of measurement errors) and b) $70.03 \pm 0.12 \mathrm{mN} / \mathrm{m}$ (eST).

The surface tension values of phosphatidylcholine:cholesterol=19:1 mixture by addition of silver nanoparticles at concentrations from 0.01 to 1.0 a.u. (arbitrary units) are presented in Table 1. 
Table 1. The surface tension (ST) values for the samples of $\mathrm{PCe} 1: \mathrm{Chol}=19: 1$ in the presence of silver nanoparticles.

\begin{tabular}{c|c|c} 
Samples & $\mathbf{t}=\mathbf{0 . 5} \mathbf{s}$ & ST at $\mathbf{t} \rightarrow \infty, \mathbf{s}$ \\
\hline PCe1+Chol $+0.01 \mathrm{Ag}$ & $72.07 \pm 0.12$ & $70.63 \pm 0.18$ \\
\hline $\mathrm{PCe} 1+$ Chol $+0.05 \mathrm{Ag}$ & $72.94 \pm 0.14$ & $72.11 \pm 0.14$ \\
\hline $\mathrm{PCe} 1+\mathrm{Chol}+0.1 \mathrm{Ag}$ & $72.88 \pm 0.11$ & $72.20 \pm 0.10$ \\
\hline $\mathrm{PCe} 1+\mathrm{Chol}+0.3 \mathrm{Ag}$ & $73.00 \pm 0.10$ & $70.76 \pm 0.11$ \\
\hline $\mathrm{PCe} 1+\mathrm{Chol}+0.5 \mathrm{Ag}$ & $72.55 \pm 0.10$ & $69.46 \pm 0.14$ \\
\hline $\mathrm{PCe} 1+$ Chol $+0.7 \mathrm{Ag}$ & $72.73 \pm 0.12$ & $71.58 \pm 0.13$ \\
\hline PCe1+Chol $+1.0 \mathrm{Ag}$ & $72.61 \pm 0.13$ & $70.83 \pm 0.12$
\end{tabular}

The data in Table 1 agree with the expected ones for a high ratio of phosphatidylcholine in the mixture and can be considered the reference data for the further mixtures studied. A small decrease of ST values (at a surface lifetime of $0.5 \mathrm{~s}$ ) and an increase of eST values (see table 1) after adding $0.01 \mathrm{a}$. u. of AgNP dispersion was obtained. It is important to highlight that the simultaneous increase observed of the ST and eST values (see table 1) was more pronounced (up to 72.94-72.88 $\mathrm{mN} / \mathrm{m}$ ) after adding 0.05-0.1 a. u. of AgNP dispersion to PCe1:Chol mixtures. This further small increase of ST values (at a surface lifetime of $0.5 \mathrm{~s}$ ) and a decrease of eST values (see table 1) after adding 0.3 a. u. of AgNP dispersion was found. The further addition of 0.5-1.0 a. u. of AgNP dispersion to PCe1:Chol mixtures did not change the ST values, whereas the eST values varied essentially (from 69.46 \pm 0.14 to $71.58 \pm 0.13$ ), but the average value was about $70.62 \pm 0.10$ that was very close to $70.63 \pm 0.18$ after adding $0.01 \mathrm{a}$. u. of AgNP dispersion (Table 1).

\subsection{Particle size changes by the interaction of AgNPs with model membranes.}

The average particle diameters, measured at the first step of $\mathrm{AgNP}$ addition (0.01 a.u.) to PCe1 mixture with cholesterol, was on $89 \%$ higher as compared to the initial PCe1:cholesterol=19:1 mixture. In contrast, the effective particle diameters, measured at the first step of AgNP addition (0.01 a.u.) to PCe1 mixture with cholesterol, were almost the same as for the initial PCe1:cholesterol=19:1 mixture (Table 2).

Table 2. The average particle diameter (APD) and effective particle diameter (EPD) values for the samples of PCe1:Chol=19:1 in the presence of silver nanoparticles.

\begin{tabular}{c|c|c} 
Samples & APD, $\mathbf{n m}$ & EPD, $\mathbf{n m}$ \\
\hline $\mathrm{ePC} 1+\mathrm{Chol}+0.01 \mathrm{Ag}$ & $152.0 \pm 0.1$ & $221.2 \pm 0.2$ \\
\hline $\mathrm{ePC} 1+\mathrm{Chol}+0.05 \mathrm{Ag}$ & $4.70 \pm 0.20$ & $201.4 \pm 0.2$ \\
\hline $\mathrm{ePC} 1+\mathrm{Chol}+0.1 \mathrm{Ag}$ & $4.10 \pm 0.10$ & $184.4 \pm 0.3$ \\
\hline $\mathrm{ePC} 1+\mathrm{Chol}+0.3 \mathrm{Ag}$ & $4.10 \pm 0.04$ & $155.6 \pm 0.1$ \\
\hline $\mathrm{ePC} 1+\mathrm{Chol}+0.5 \mathrm{Ag}$ & $3.20 \pm 0.10$ & $128.1 \pm 0.2$ \\
\hline $\mathrm{ePC} 1+\mathrm{Chol}+0.7 \mathrm{Ag}$ & $3.10 \pm 0.03$ & $112.4 \pm 0.1$ \\
\hline $\mathrm{ePC} 1+\mathrm{Chol}+1.0 \mathrm{Ag}$ & $3.10 \pm 0.03$ & $96.0 \pm 0.1$
\end{tabular}

During an increase of AgNPs concentration up to 0.05 a.u. the average particle diameter decreased drastically (by 30 times), whereas the effective particle diameter decreased by $10 \%$ only (see table2). The further increase of AgNPs concentration up to $0.3 \mathrm{a}$.u. led to the average particle diameter decrease by $32 \%$ and the effective one - by $10 \%$ in these mixtures. There are no significant changes in the average particle diameter and the effective one in the case of the synthetic PC-containing samples. In general, an increase in AgNP concentration in dispersion samples by every 0.2 a.u. led to a decrease in the samples' effective particle diameter by 15 $17 \%$ (Table 2). 


\subsection{Surface tension changes by the interaction of lipase with model membranes.}

It was interesting to study an enzyme interaction, such as lipase from the hog pancreas (instead of the AgNPs), with the same model membranes. A lipase addition to the all twocomponent mixtures at concentrations of $0.01,0.05,0.1$, and 0.5 a.u. led to the significant (up to $10 \%$ ) ST decrease in average.

Table 3. The surface tension (ST) values for the samples of PCe1:Chol=19:1 in the presence lipase (PPL).

\begin{tabular}{c|c|c} 
Samples & $\mathbf{t}=\mathbf{0 . 5} \mathbf{~}$ & $\mathbf{S T}$ at $\mathbf{t} \rightarrow \infty, \mathbf{s}$ \\
\hline PCe1+Chol +0.01 PPL & $72.37 \pm 0.12$ & $71.91 \pm 0.18$ \\
\hline PCe1+ Chol +0.05 PPL & $72.22 \pm 0.14$ & $71.80 \pm 0.14$ \\
\hline PCe1+ Chol +0.1 PPL & $72.01 \pm 0.11$ & $71.53 \pm 0.10$ \\
\hline PCe1+ Chol +0.5 PPL & $72.08 \pm 0.10$ & $71.75 \pm 0.14$ \\
\hline PCe1+ Chol +1.0 PPL & $72.12 \pm 0.13$ & $71.43 \pm 0.12$
\end{tabular}

A small continuous decrease of ST values (at a surface lifetime of $0.5 \mathrm{~s}$ ) and eST (ST at $t \rightarrow \infty$ ) values (Table 3 ) after adding from 0.01 to $0.1 \mathrm{a}$. $\mathrm{u}$. of PPL dispersion was found. It is important to highlight that a very small increase that was observed for the ST and eST values (see table 3) after adding 0.5 a. u. of PPL dispersion to PCe1:Chol mixtures was almost in the experimental error ranges. A further small decrease of ST and eST values (Table 3) after adding 1.0 a. u. of PPL dispersion was found.

\subsection{Particle size changes by the interaction of lipase with model membranes.}

The average and effective particle diameters, measured at the first step of lipase addition (0.01 a.u.) to PCe1 mixture with cholesterol (Table 4), was almost the same as for the initial PCe1:cholesterol=19:1 mixture.

Table 4. The average particle diameter (APD) and effective particle diameter (EPD) values for the samples of PCe1:Chol=19:1 in the presence of lipase (PPL).

\begin{tabular}{c|c|c} 
Samples & APD, $\mathbf{n m}$ & EPD, $\mathbf{n m}$ \\
\hline $\mathrm{ePC} 1+$ Chol +0.01 PPL & $57.6 \pm 0.1$ & $243.2 \pm 0.1$ \\
\hline $\mathrm{ePC} 1+$ Chol +0.05 PPL & $45.3 \pm 0.2$ & $238.8 \pm 0.2$ \\
\hline $\mathrm{ePC} 1+$ Chol +0.1 PPL & $117.1 \pm 0.3$ & $218.4 \pm 0.3$ \\
\hline ePC1+ Chol +0.5 PPL & $167.8 \pm 0.2$ & $247.8 \pm 0.2$ \\
\hline ePC1+ Chol +1.0 PPL & $226.6 \pm 0.1$ & $239.9 \pm 0.1$
\end{tabular}

During an increase of lipase concentration up to 0.05 a.u. the average particle diameter decreased by $21 \%$, whereas the effective particle diameter decreased slightly by $2 \%$ only (see table 4). The further increase of lipase concentration up to $1.0 \mathrm{a} . \mathrm{u}$. led to the average particle diameter increase by 2 times and the effective one - by about 10\%. During an increase of lipase concentration up to 0.5 or 1.0 a.u. the average particle diameter increased by 3 or 4 times compared to those at PPL 0.01 a.u., whereas the effective particle diameter was almost the same these conditions (Table 4).

In general, the average particle diameter (APD) values changed drastically, whereas the effective particle diameter (EPD) values were almost the same by addition lipase from 0.01 to 1.0 a.u. (Table 4 ).

The obtained data agree with the found data on the activity of the lipase and their mixtures with some surfactants, lipids, and polymers [34-36]. 


\section{Conclusions}

Thus, an addition of silver nanoparticles led to a decrease both in ST and eST, whereas almost no changes occurred by lipase addition. The addition of AgNPs leads to the destruction of the large lipid particles, i.e., the appearance of particles of very small diameter. Probably, the decrease in ST occurs more significantly with a narrower particle size distribution; but the appearance of the small particles does not play a significant role in the eST decrease. The average lipid particle diameter values changed drastically, whereas the effective particle diameter values were almost the same by lipase addition. Thus, AgNPs or lipase interactions with the mixture of natural phospholipid and cholesterol have been studied for the first time and have had entirely different features. A further comparative study of the inorganic and organic compounds with such models of biological membranes for both fundamental and applied aspects seems interesting.

\section{Funding}

This research was funded by a grant from the Russian Foundation for Basic Research, project No. 19-03-00717 (parts 1 , 2, 3.1., 3.2); a grant from the Russian Science Foundation, project No. 20-16-00032 (parts 3.3, 3.4).

\section{Acknowledgments}

The authors are thankful to A.A. Savina for AgNPs' preparations.

\section{Conflicts of Interest}

The authors declare no conflict of interest.

\section{References}

1. Pacioni, C.D.; Borsarelli, V.R.; Veglia, A.V. Synthetic routes for the preparation of silver nanoparticles. In Book Silver nanoparticle applications, Griffith, M., Udekwu, K.I., Gkotzis, S., Mah, T.F., Alarcon, E.I. Eds.; Springer International Publishing: Cham, Switzerland, 2015, 13-46. https://doi.org/10.1007/978-3-03031261-9.

2. Alwis Weerasekera, H.; Griffith, M.; Alarcon, E.I. Biomedical Uses of Silver Nanoparticles: From Roman Wine Cups to Biomedical Devices. In Book Silver nanoparticle applications, Griffith, M., Udekwu, K.I., Gkotzis, S., Mah, T.F., Alarcon, E.I. Eds.; Springer International Publishing: Cham, Switzerland 2015, 93125. https://doi.org/10.1007/978-3-030-31261-9.

3. Terenteva, E.A.; Apyari, V.V.; Dmitrienko, S.G.; Zolotov, Y.A. Formation of plasmonic silver nanoparticles by flavonoid reduction: A comparative study and application for determination of these substances. Spectrochim Acta A Mol Biomol Spectrosc. 2015, 151, 89-95. https://doi.org/10.1016/j.saa.2015.06.049.

4. Kim, J.S. et al. Antimicrobial effects of silver nanoparticles. Nanomedicine: nanotechnologies, biology and medicine 2007, 3, 95-101. https://doi.org/10.1016/j.nano.2006.12.001.

5. Krutakov, J.A.; Kudrinsky, A.A.; Olenin, A.Y.; Lisichkin, G.V. Synthesis and properties of silver nanoparticles: achievements and prospects. Russ. Chem. Rev. 2008, 77, 233-257. https://doi.org/10.1070/RC2008v077n03ABEH003751.

6. Eremeev, N.L.; Zaitsev, S.Yu. Porcine Pancreatic Lipase as a Catalyst in Organic Synthesis. Mini-Reviews in Organic Chemistry. 2016. 13, 78-85. https://doi.org/10.2174/1570193X13666160225000520.

7. Vasileva, P.; Alexandrova, T.; Karadjova, I. Application of Starch-Stabilized Silver Nanoparticles as a Colorimetric Sensor for Mercury(II) in 0.005 mol/L Nitric Acid. Journal of Chemistry 2017, 2017, Article ID 6897960. https://doi.org/10.1155/2017/6897960. 
8. Chen, Z.; Zhang, X.; Cao, H.; Huang, Y. Chitosan-capped silver nanoparticles as a highly selective colorimetric probe for visual detection of aromatic ortho-trihydroxy phenols. Analyst 2013, 138, 2343-2349. https://doi.org/10.1039/c3an36905f.

9. Baruah, B.; Kiambuthi, M. Facile synthesis of silver and bimetallic silver-gold nanoparticles and their applications in surface-enhanced Raman scattering. RSC Adv. 2014, 4, 64860-64870. https://doi.org/10.1039/C4RA09956G.

10. Bothun, G.D. Hydrophobic silver nanoparticles trapped in lipid bilayers: Size distribution, bilayer phase behavior, and optical properties. Nanobiotechnol. 2008, 6, 13-20. https://doi.org/10.1186/1477-3155-6-13.

11. Yaqoob, A.A.; Umar, K.; Ibrahim, M.N.M. Silver nanoparticles: various methods of synthesis, size affecting factors and their potential applications-a review. Appl Nanosci. 2020, 10, 1369-1378. https://doi.org/10.1007/s13204-020-01318-w.

12. Skiba, M.I.; Vorobyova, V.I.; Pivovarov, A.; Makarshenko, N.P. Green Synthesis of Silver Nanoparticles in the Presence of Polysaccharide: Optimization and Characterization. Journal of Nanomaterials. 2020, 2020, Article ID 3051308. https://doi.org/10.1155/2020/3051308.

13. Wei, Simin; Wang, Yinghui; Tang, Zhishu; Xu, Hongbo; Wang, Zhe; Yang, Tian; Zou Taiyan. A novel green synthesis of silver nanoparticles by the residues of Chinese herbal medicine and their biological activities. RSC Adv. 2020, 11, 1411. https://doi.org/10.1039/D0RA08287B.

14. Zaitsev, S.Yu.; Solovyeva, D.O.; Nabiev, I. Thin films and assemblies of photosensitive membrane proteins and colloidal nanocrystals for engineering of hybrid materials with advanced properties. Advances in Colloid and Interface Science. 2012, 183-184, 14-29. http://dx.doi.org/10.1016/j.cis.2012.07.003

15. Shanmugapriya, Karuppusamy; Palanisamy, Subramanian; Boomi, Pandi; Subaskumar, Rathinasamy; Ravikumar, Sundaram; Thayumanavan, Thangavelu. An eco-friendly Gnaphalium polycaulon mediated silver nanoparticles: Synthesis, characterization, antimicrobial, wound healing and drug release studies. Journal of Drug Delivery Science and Technology, 2021, 61, 102202. https://doi.org/10.1016/j.jddst.2020.102202.

16. Shankar, Akshay; Kumar, Vinod; Kaushik, Naveen Kumar; Kumar, Anil; Malik, Vinay; Singh, Davender; Singh, Bijender. Sporotrichum thermophile culture extract-mediated greener synthesis of silver nanoparticles: Eco-friendly functional group transformation and anti-bacterial study. Current Research in Green and Sustainable Chemistry, 2020, 3, 100029. https://doi.org/10.1016/j.crgsc.2020.100029.

17. Aiswariya, K. S.; Jose, Vimala. Photo-Mediated Facile Synthesis of Silver Nanoparticles Using Curcuma zanthorrhiza Rhizome Extract and Their In Vitro Antimicrobial and Anticancer Activity. J. Inorg. Organomet. Polym. 2021, Article ID 021-01951-0. https://doi.org/10.1007/s10904-021-01951-0.

18. Solaiman, Mostafa A.; Ali, Mohamed A.; Abdel-Moein, Nadia M.; Mahmoud, Ebtesam A. Synthesis of AgNPs developed by green-chemically method and evaluation of antioxidant activities and anti-inflammatory of synthesized nanoparticles against LPS-induced NO in RAW 264.7 macrophages. Biocatalysis and Agricultural Biotechnology, 2020, 29, 101832. https://doi.org/10.1016/j.bcab.2020.101832.

19. Lagashetty, Arunkumar; Ganiger, Sangappa K.; Preeti, R. K.; Reddy, Shashidhar; Pari, Malathesh. Microwave-assisted green synthesis, characterization and adsorption studies on metal oxide nanoparticles synthesized using Ficus Benghalensis plant leaf extracts. New J. Chem. 2020, 44, 14095-14102. https://doi.org/10.1039/D0NJ01759K.

20. Wang, Yinghui; Wei, Simin; Wang, Kang; Wang, Zhe; Duan, Jinwei; Cui, Lin; Zheng, Huayu; Wang, Ying; Wang, Shanshan. Evaluation of biosynthesis parameters, stability and biological activities of silver nanoparticles synthesized by Cornus Officinalis extract under $365 \mathrm{~nm}$ UV radiation. RSC Adv., 2020, 10, 27173-27182. https://doi.org/10.1039/D0RA04482B.

21. Sharma, R.; Chisti, Y.; Banerjee, U.C. Production, purification, characterization, and applications of lipases. Biotechnology Advances 2001, 19, 627-62. https://doi.org/10.1016/s0734-9750(01)00086-6.

22. Javed, S.; Azeem, F.; Hussain, S.; Rasul, I.; Siddique, M.H.; Riaz, M.; Afzal, M.; Kouser, A.; Nadeem, H. Bacterial lipases: A review on purification and characterization. Progress in Biophysics and Molecular Biology 2018, 132, 23-34. https://doi.org/10.1016/j.pbiomolbio.2017.07.014.

23. Treichel, H,; de Oliveira, D.; Mazutti, M.A.; Di Luccio, M.; Oliveira, J.V. A review on microbial lipases production. Food Bioprocess Technology 2010, 3, 182-96. https://doi.org/10.1007/s11947-009-0202-2.

24. Gupta, R.; Gupta, N.; Rathi, P. Bacterial lipases: an overview of production, purification and biochemical properties. Applied Microbiology and Biotechnology 2004, 64, 763-81. https://doi.org/10.1007/s00253-004$1568-8$. 
25. Robles-Medina, A.; Gonzalez-Moreno, P.A.; Esteban-Cerdan, L.; Molina-Grima, E. Biocatalysis: Towards ever greener biodiesel production. Biotechnol Adv 2009, 27, 398-408. https://doi.org/10.1016/j.biotechadv.2008.10.008.

26. Sangeetha, R. Bacterial lipases as potential industrial biocatalysts: An overview. Res J Microbiol 2011, 6, 124. https://dx.doi.org/10.3923/jm.2011.1.24.

27. Salihu, A.; Alam, M.Z. Solvent tolerant lipases: A review. Process Biochemistry 2015, 50, 86-96. https://doi.org/10.1016/j.procbio.2014.10.019

28. Jaeger, K.-E.; Dijkstra, B.W. K.-E.; Reetz, M.T. Bacterial biocatalysts: Molecular Biology, ThreeDimensional Structures and Biotechnological Applications of Lipases. Annual Review of Microbiology 1999, 53, 315-351. https://doi.org/10.1146/annurev.micro.53.1.315.

29. Jaeger, K.-E.; Eggert, T. Lipases for biotechnology. Current Opinion in Biotechnology 2002, 13, 390-97. https://doi.org/10.1016/s0958-1669(02)00341-5.

30. Jaeger, K.-E.; Reetz, M.T. Microbial lipases form versatile tools for biotechnology. Trends in Biotechnology 1998, 16, 396-403. https://doi.org/10.1016/s0167-7799(98)01195-0.

31. Andualema, B.; Gessesse, A. Microbial Lipases and Their Industrial Applications: Review. Biotechnology 2012, 11, 100-118. https://dx.doi.org/10.3923/biotech.2012.100.118.

32. Zaitsev, S.Yu.; Savina, A.A.; Zaitsev, I.S. Biochemical aspects of lipase immobilization at polysaccharides for biotechnology. Advances in Colloid and Interface Science 2019, 272, 1-14. https://doi.org/10.1016/j.cis.2019.102016.

33. Zaitsev, S.Yu. Dynamic surface tension measurements as general approach to the analysis of animal blood plasma and serum. Advances in Colloid and Interface Science 2016, 235, 201-213. https://doi.org/10.1016/j.cis.2016.06.007.

34. Zaitsev, S.Yu.; Bogolyubova, N.V; Zhang, X.; Brenig, B. Biochemical parameters, dynamic tensiometry and circulating nucleic acids for cattle blood analysis: a review. PeerJ. 2020, 8, 1-24. https://doi.org/10.7717/peerj.8997

35. Savina, A.A.; Abramova, O.V.; Garnashevich, L.S.; Zaitsev, I.S.; Voronina, O.A.; Tsarkova, M.S.; Zaitsev, S.Yu. Study of Catalytic Activity of Lipase and Lipase-Chitosan Complexes in Dynamics. Journal of Research Updates in Polymer Science, 2019, 8, 15-20.

36. Zaitsev, S.Y.; Savina, A.A.; Garnashevich, L.S.; Tsarkova, M.S.; Zaitsev, I.S. Effect of Some Charged Polymers on the Activity of Pancreatic Porcine Lipase. BioNanoSci. 2019, 9, 773-777. https://doi.org/10.1007/s12668-019-00677-1. 